\title{
O currículo de Educação Física no Ensino Médio do estado de São Paulo na voz dos professores: uma avaliação pré-reforma
}

\author{
The high school Physical Education curriculum in the state of São \\ Paulo according to teachers: a pre-reform evaluation
}

\section{I currículo de Educación Física en la escuela secundaria del estado de São Paulo en la voz de los profesores: una evaluación pre-reforma}

Gabriel Francisco Zago Pacheco'

https://orcid.org/0000-0002-7744-544I

Sérgio Roberto Silveira²

https://orcid.org/0000-000I-9171-0777

\begin{abstract}
Resumo: $O$ objetivo do artigo foi investigar percepções de professores de Educação Física do ensino médio do Estado de São Paulo acerca do currículo, em face das próprias experiências e possíveis impactos na reforma curricular. Interpretaram-se, através de estatística descritiva e análise de conteúdo, as respostas online de 53 professores, analisando: utilização do currículo, reforma do ensino médio (BRASIL, 2018) e identidade da Educação Física (TANI, 20II). Constatou-se que professores apreendem o currículo em função dos conteúdos, especialmente, "esporte" e "saúde", entendendo ser esta a principal ênfase de uma revisão. Presumiu-se uma situação de conflito para a educação física no ensino médio com a reforma curricular, dado seu enquadramento na área de Linguagens, a ausência de um delineamento epistemológico e a necessidade de considerar como pensam e atuam seus atores na prática docente.
\end{abstract}

Palavras-chave: Educação Física Escolar. Currículo. Prática docente.

Abstract: The research aimed to investigate Physical Education-PE teachers' perceptions through their own professional experiences supported by the official high school curriculum in São Paulo State and their possible impacts on the curricular reform. Answers to an online questionnaire sent to 53 teachers were interpreted using descriptive statistics and content analysis considering: the use of the curriculum, the national level-based reform BNCC (BRASIL, 20I8) and PE identity (TANI, 20II). Our results revealed that the curriculum is specially apprehended in its "sports" and "health" contents, since the teachers understand these aspects as the focus of

\footnotetext{
' Mestre em Ciências pela Escola de Educação Física e Esporte da Universidade de São Paulo. Professor de Educação Física no município de São Paulo - EEFE-USP. E-mail: gfzpacheco@gmail.com

${ }^{2}$ Pós-doutor em Educação Física pela Escola de Educação Física e Esporte da Universidade de São Paulo (EEFEUSP), e Universidade Estadual Paulista - UNESP. Professor assistente do Departamento de Pedagogia do Movimento do Corpo humano da EEFE-USP. E-mail: ssilveira@usp.br
}

Olhar de professor, Ponta Grossa, v. 24, p. I-2I, e-I5233.010, 2021.

Disponível em <https://revistas2.uepg.br/index.php/olhardeprofessor> 
O currículo de Educação Física no Ensino Médio do estado de São Paulo na voz dos professores...

the incoming reform. A conflicting scenario regarding PE was assumed, given the awaited changes, the inclusion of the subject in the Language are, the absence of a strengthening epistemological outline, and the need to consider how these professionals think and act in their teaching activities.

Keywords: Physical Education. Curriculum. Teaching.

Resumen: El objetivo de este artículo fue investigar las diversas comprensiones de profesores de Educación Física Escolar-EFE de secundaria del departamento de São Paulo sobre el currículo, frente a sus propias experiencias profesionales y los posibles impactos de la reforma curricular. Se interpretaron las respuestas por internet de 53 profesores, por medio de estadística descriptiva y análisis de contenidos, analizando: el uso del currículo, la reforma de la enseñanza media (BRASIL, 20I8) y la identidad de la Educación Física (TANI, 20II). Se constató que los docentes se apropian del currículo actual en función de los contenidos, especialmente deporte y salud, entendidos como el principal énfasis de la revisión. Se asumió una situación conflictiva para la EFE frente a la reforma curricular, dado su encuadre en el área de Lenguajes, la ausencia de diseño epistemológico y la necesidad de considerar cómo piensan y actúan sus actores en la práctica docente.

Palabras-clave: Educación física Escolar. Currículo. Práctica docente.

\section{Introdução}

A pesquisa desenvolvida buscou investigar as percepções de professores de educação física escolar- EFE do ensino médio- EM da rede pública acerca do currículo do Estado de São Paulo, a partir das experiências advindas de sua utilização na atuação profissional, com o intuito de refletir em que medida tais considerações poderiam ser utilizadas na reforma curricular do EM no Estado de São Paulo.

A promulgação da Lei I3.4I5/I7 (BRASIL, 20I7) e a aprovação do trecho referente ao ensino médio na Base Nacional Comum Curricular - BNCC (BRASIL, 20I8) em nível federal tende a gerar consideráveis mudanças estruturais no EM, cuja administração pública é majoritariamente pertencente aos estados da federação, que devem atender aos requisitos estabelecidos no documento, o que, por sua vez, implica em alterações nos currículos estaduais e promoverá modificações profundas na organização escolar e na prática docente (SILVEIRA, 2019).

As escolas do governo do Estado de São Paulo são especificamente orientadas por um currículo em vigor desde $20 \mathrm{I}$ I (SÃO PAULO, 20I I), posto em execução enquanto proposta curricular desde 2008 (SÃO PAULO, 2008). Um rigoroso trabalho de implementação deste documento, juntamente com seus materiais de apoio, cadernos de professor e cadernos de aluno, foi feito ao longo de 12 anos, com a promoção de cursos de formação aos professores atuantes na rede e discussões em âmbitos regionais (Diretorias Regionais de Ensino) e locais (em cada escola). Desse modo, entendese que os professores de educação física que atuaram e atuam em escolas de EM da rede pública estadual no decorrer de mais de uma década possuem um conjunto de informações, resultados de experiências e encaminhamentos oriundos de suas práticas docentes que deveriam ser considerados numa reforma curricular.

Diante do recente cenário de mudança advindo da Lei I3.4I5/I7 (BRASIL, 20I7) e da BNCC do EM (BRASIL, 20I8), percebe-se a carência de uma avaliação mais acurada sobre como o currículo

Olhar de professor, Ponta Grossa, v. 24, p. I-2I, e-I5233.010, 202 I.

Disponível em <https://revistas2.uepg.br/index.php/olhardeprofessor> 
do Estado de São Paulo foi percebido, apropriado e utilizado pelos seus professores nesse período. Entende-se que, somente a partir de uma análise mais aprofundada desses quesitos, uma reforma curricular poderia ser feita para os diferentes níveis de ensino.

Destaca-se que os prazos previstos em lei para a implementação de mudanças nas políticas educativas se desenrolam em tempo exíguo, fazendo com que os estados acelerem as diversas fases que comportam o processo de reelaboração curricular. Este processo aligeirado cria um contexto impeditivo para que uma rede com o tamanho do ensino público estadual de São Paulo contemple interlocuções com os personagens centrais do processo ensino e aprendizagem, representados pelos professores(as) e, também, por alunos(as) e comunidade escolar.

Observando os documentos oficiais, é possível notar que a EFE está nacionalmente inserida na educação básica na área de Linguagens (BRASIL, 1996, 2017, 2018). Entretanto, em sua história particular como área do conhecimento, a EFE vem sofrendo com consequências oriundas de uma crise de identidade no campo científico da própria Educação Física. Tal fato gera múltiplas distorções, atingindo inclusive a percepção dos professores especialistas da educação básica em relação às concepções sobre: o estatuto da disciplina de EFE; o quê e como ensinar; e como avaliar a aprendizagem - problemáticas que, por sua vez, certamente geram dificuldades na qualidade da prática docente.

Acrescentam-se a essas questões as famigeradas condições de trabalho que levam os profissionais de EFE a terem pouco tempo e disponibilidade para envolvimento em processos de formação continuada, com a oportunidade de interlocução com pesquisadores no campo da educação e da educação física, que têm por missão a produção e a disseminação de conhecimentos a partir da pesquisa científica.

Nesse contexto, a reforma curricular do EM a partir da BNCC (BRASIL, 2018) parece se desenhar num cenário no qual os caminhos percorridos pelos representantes de órgãos centrais na elaboração dos currículos pouco se cruzam com os profissionais do magistério que exercem a prática docente nas escolas e tampouco com aqueles que devem produzir conhecimento nas Universidades. Negligenciada essa articulação e não havendo consenso entre os representantes da área, existe a possibilidade de que vulnerabilidades materializadas nas intenções e nos conteúdos do componente Educação Física se perpetuem nos documentos oficiais, atingindo docentes no ensino básico. (CORREIA, 2016).

Com base no exposto acima, se apresentam como premissas de análise: (I) que professore(as) de EFE, perdidos(as) na indefinição da identidade de área, encontram as suas próprias formas de exercer a prática docente, ajustando a utilização do currículo com o qual são obrigados a trabalhar às concepções pessoais; (2) os(as) professores(as) têm conhecimentos e percepções oriundos da prática 
O currículo de Educação Física no Ensino Médio do estado de São Paulo na voz dos professores...

docente que podem e devem ser considerados na elaboração de reformas curriculares; e (3) em decorrência das conhecidas demandas advindas da prática docente no cotidiano escolar, as percepções dos(as) professores(as) sobre possíveis alterações no currículo definitivamente incidirão sobre "o quê ensinar". Nesse âmbito, emerge a questão central desta investigação: Como as percepções dos professores de EFE do EM acerca do currículo poderiam influenciar no processo de estruturação da reformulação curricular?

\section{O Ensino Médio no Brasil, currículo e prática docente}

Globalmente, a educação e suas etapas são frequentemente tópicos das mais acaloradas discussões, dada sua relação intrínseca com questões sociais, econômicas e políticas das nações. Mudanças nas políticas públicas que dizem respeito aos objetivos e à oferta da etapa do EM no país são influenciadas pelas transformações no mundo do trabalho que vêm acontecendo mais intensamente na segunda metade do século XX. Para Kuenzer (2000), é relevante destacar a necessidade de universalização dessa etapa de ensino, visto que a formação do jovem para as próximas décadas não pode prescindir de uma sólida base educativa que consiga unir o fazer e o pensar aprendidos na escola.

Segundo Krawczyk (2009), com o foco na universalização e a consequente ampliação de oferta, o EM tem sido marcado por tensões relacionadas ao seu sentido norteador ideal, qual seja: a formação para a cidadania; para o mercado de trabalho; ou para o ensino superior. Na LDB 9394/96 (BRASIL, 1996), encontra-se a expectativa de que o EM supere a oposição do profissionalizante versus propedêutico, integrando ambas as formações num único currículo. Ressalta-se ainda que a ideia de formatar o EM numa "base comum" associada à outra parte que é diversificada de acordo com as demandas regionais, como recentemente concretizado na Base Nacional Comum Curricular (BRASIL, 2018), está expressa desde a LDB 9394/96 (BRASIL, 1996).

Das inúmeras reflexões sobre o currículo, utiliza-se nesta pesquisa a ideia de "tradição inventada" de Goodson (2002), complementada por Macedo (2007), no sentido de currículo visto como um artefato socioeducacional que expressa interesses formativos a partir da concepção, organização, seleção e implementação de conhecimentos e saberes.

Faz-se relevante destacar, segundo Lopes e Macedo (20II), que o formato de currículo "tradicionalmente" pautado em objetivos, métodos e avaliação reconhecido atualmente nos próprios documentos oficiais de grande difusão, carrega na sua gênese uma concepção que remete ao fim da primeira metade do século $X X$ e permanece no imaginário social com este tipo de padronização.

No entanto, mesmo que Silveira (2019) destaque que o currículo implícita ou explicitamente manifeste as características de uma política pública e de uma gestão de governo, Gómez \& Sacristán (2000) afirmam que as finalidades do currículo podem frequentemente se tornar meras declarações de

Olhar de professor, Ponta Grossa, v. 24, p. I-2I, e-15233.010, 2021.

Disponível em <https://revistas2.uepg.br/index.php/olhardeprofessor> 
intenções, que ficariam à mercê da prática docente e do contexto escolar. Afinal, é a partir de uma combinação de forças entre o que é oficial (currículo), coletivo, regional e, finalmente, do que é pessoal do(a) professor(a), que se constrói a prática docente.

Superando o princípio de que ser professor - "professar" um saber - ou "praticar a docência" é ensinar (marcar, insignare - do latim), Roldão (2007) e Correia (20I I) definem a prática docente como ato de educar e ensinar transformando saberes prévios em ação. Todavia, existe uma complexidade na prática docente que ultrapassa o simples conceito de ensinar, dadas as condições peculiares em que o ato acontece. $O$ intuito aqui é destacar que, embora os processos educativos - a saber, o que se entende por "ensinar" - ocorram em diversas instâncias da sociedade, sob diversas justificativas e regras (através dos pais e familiares, no transporte, nas atividades religiosas, etc.), de modo peculiar vão se constituir no contexto escolar. Com base nesse fato, Franco (2016) e Gómez e Sacristán (2000) entendem a prática docente a partir do conceito de práxis, enquanto uma ação reflexiva, consciente e participativa, de caráter multidimensional.

Para Silveira e Pacheco (2019), professores(as) de EFE buscam desenvolver seus planejamentos, tomando decisões relativas à seleção de conteúdos e metodologias que irão operacionalizar em situações de ensino, levando em conta a avaliação das respectivas atuações profissionais, de forma ética e de acordo com as requisições dos documentos curriculares e projetos político-pedagógicos das próprias escolas. Entretanto, os autores alertam que, individualmente, a prática docente é emoldurada com formato próprio de cada professor, o que convencionaram chamar de Teacher's knack idiossincrasia de sua intervenção profissional.

\section{A Educação Física, sua presença no currículo do Ensino Médio no estado de São Paulo e a reforma curricular}

Mesmo um olhar en passant sobre a EFE nos documentos oficiais é capaz de confirmar sua presença constante nos currículos e leis vigentes ao longo do século $X X$, como, por exemplo, nas Leis de Diretrizes e Bases da Educação Nacional, Lei 4.024/6I (BRASIL, I96I), Lei 5.692/7I (BRASIL, I97I), Lei 9.394/96 (BRASIL, 1996), nos Parâmetros Curriculares Nacionais (1998) e, em específico, no Currículo do Estado de São Paulo (SÃO PAULO, 20II), alvo deste trabalho.

Entretanto, uma observação mais cuidadosa traz à superfície a indefinição da Educação Física como área de conhecimento, condição que configura um fator complicador extremamente relevante, pois, segundo Tani (1996, 1998, 20I I), produz ambiguidades em relação aos seus objetivos, significados e conteúdos como disciplina escolar. Destacando um apontamento importante do autor, a depender da interlocução, além de disciplina, à Educação Física se podem atribuir outros significados: de uma profissão, de um curso de formação profissional ou de uma área do conhecimento científico.

Olhar de professor, Ponta Grossa, v. 24, p. I-2I, e-I5233.010, 2021.

Disponível em <https://revistas2.uepg.br/index.php/olhardeprofessor> 
O currículo de Educação Física no Ensino Médio do estado de São Paulo na voz dos professores...

Consequentemente, ao elaborarem um currículo de Educação Física para o EM, os órgãos estaduais subtraem certos conhecimentos para serem disseminados pelo componente curricular de uma área acadêmica fragilizada em seu campo epistemológico, num processo invariavelmente permeado por problemas imanentes à educação física vista como ciência carente de um corpo de conhecimentos bem estabelecido.

A despeito dos caminhos percorridos na seleção prévia de conhecimentos, Correia (2016) destaca que os conteúdos presentes na disciplina de EFE na escola recebem um "incremento didático e metodológico", já que estes existem também fora dela como produções da cultura. Para o autor, o "trato pedagógico" deve ser dado pelos(as) professores(as) em relação aos critérios para selecionar "o quê", "para quem", "como" e "quando ensinar": Aceitando esta premissa, entende-se que a reforma curricular do EM no Estado de São Paulo a partir da BNCC deveria levar em conta que os professores de EFE esbarram nas dúvidas sobre quais são os tipos de conhecimentos da área da educação física que deveriam ser ensinados na escola.

Projetando uma possível solução para o problema da EFE, Tani (201I) propõe que a disciplina abarque a aprendizagem do, através e sobre o movimento humano - tendo como referência a cultura de movimento, com ênfases diferentes, de acordo com a faixa etária. Todavia, para a proposta se efetivar, há necessidade do alinhamento de produções científicas na área para a constituição de uma base específica de conhecimentos que fomente a EFE.

No ano de 201 I, o currículo da rede pública estadual de São Paulo, superando o caráter de proposta curricular de 2008, foi implementado seguindo uma divisão em áreas de conhecimento, sendo a área chamada de "Linguagens, códigos e suas tecnologias" a expressão coletiva das disciplinas de Língua Portuguesa, Língua Estrangeira Moderna, Arte e Educação Física (SÃO PAULO, 2008, 20I I).

A Educação Física é, então, apresentada no documento como o componente curricular que tem por finalidade levar ao aluno:

[...] a compreensão do jogo, do esporte, da ginástica, da luta e da atividade rítmica como fenômenos socioculturais, em sintonia com os temas do nosso tempo e das vidas dos alunos, ampliando os conhecimentos no âmbito da cultura de movimento; e a ampliação das possibilidades de Se-Movimentar e dos significados/sentidos das experiências de Se-Movimentar [...], rumo à construção de uma autonomia crítica e autocrítica (SÃO PAULO, 20II, p.228).

Com relação à organização metodológica, o currículo de educação física para o EM apresenta eixos de conteúdo (jogo, esporte, ginástica, luta e atividade rítmica) entrecruzados com eixos temáticos (corpo, saúde e beleza; mídias; lazer e trabalho e contemporaneidade). Acompanham o currículo, ainda, os cadernos do professor e do aluno como materiais de apoio ao trabalho pedagógico (SÃO PAULO, 2008, 20 I I). Nesse aspecto, se faz importante ressaltar que, a partir de 2008, os professores atuantes

Olhar de professor, Ponta Grossa, v. 24, p. I-2I, e-I5233.010, 2021.

Disponível em <https://revistas2.uepg.br/index.php/olhardeprofessor> 
na rede foram convidados, bem como os candidatos aprovados nos concursos públicos posteriormente convocados, para o curso de formação continuada criado pela SEE de São Paulo. O objetivo do curso envolve a promoção e a preparação dos(as) professores(as) no que tange, especificamente, à atuação com o currículo, visando complementar a formação inicial e potencializar suas ações como profissionais da educação (SÃO PAULO, 2016).

Com a homologação da BNCC para o EM (BRASIL, 20I8), uma reforma curricular deve ser implantada em todos os estados da federação. No caso do EM, Silveira (2019) ressalta que a modificação no artigo $26, \S^{\circ}$ da Lei $9394 / 96$, para o Art.35-A, $\S 2^{\circ}$, implica que o currículo seja redimensionado pela BNCC (BRASIL, 2018) a partir de uma novidade: os itinerários formativos, estruturados em diferentes arranjos curriculares, em conformidade com a relevância para o contexto local e as possibilidades dos sistemas de ensino.

Dada a homologação pelo Conselho Nacional de Educação da BNCC do EM (BRASIL, 20I8), o autor ainda aponta o fato de que a EFE deixa de existir como componente na matriz curricular. Presume-se que esta situação levará a EFE e seus representantes, os(as) professores(as), a atravessarem um novo momento, repleto de incertezas a partir de mudanças significativas nos currículos escolares, já que a Lei 13.4I5/I7 (BRASIL, 2017), que altera a LDB 9394/96, prevê apenas "estudos e práticas de Educação Física no Ensino Médio", sem estabelecer seus conteúdos, gerando interpretações nebulosas acerca do seu papel, da sua relevância no currículo (SILVEIRA, 2019) e - por que não acrescentar produzindo mais dúvidas sobre "o quê ensinar". Portanto, a EFE não é apresentada como um componente curricular na BNCC do EM (BRASIL, 20I8), marcando apenas uma presença indireta em determinadas competências e habilidades do EM na área de Linguagens.

Acerca da caracterizada perda de espaço da EFE na BNCC do EM (BRASIL, 20I8), vale destacar a posição de Correia (2016), que alertou sobre o caráter possivelmente temporário e mutável da presença da Educação Física nos currículos, a despeito de sua frequência consistente nos documentos oficiais, que são atravessados por constantes disputas, como as evidenciadas na elaboração da BNCC (BRASIL, 2018).

Destarte, torna-se importante ressaltar que uma avaliação com maior profundidade e abrangência sobre a percepção dos(as) professores(as) no que diz respeito ao Currículo do Estado de São Paulo, em vigência há mais de uma década, aparenta ser crucial para receber a prenunciada reforma curricular. Como afirma Neira (20I8), a proposta da BNCC (BRASIL, 20I8) não apresenta diálogo com os conhecimentos já existentes sobre o ensino de EFE, trazendo novas regras e orientações que podem produzir mais distorções do que acertos em relação à prática docente em EFE.

Além de seu intrínseco problema de identidade, a EFE foi alocada no currículo do Estado de São Paulo (SÃO PAULO, 20I I) como uma disciplina da área de "Linguagens", formato reproduzido na 
O currículo de Educação Física no Ensino Médio do estado de São Paulo na voz dos professores...

BNCC (BRASIL, 20I8). Entende-se que professores(as) de EFE, atuando com conhecimentos adquiridos nos cursos de formação profissional (inicial e continuada), associados ao que entendem por cultura corporal ou movimento humano, ainda não identificam a EFE como disciplina pertencente à área de "Linguagens", outrossim, enxergando-a essencialmente vinculada à área da saúde. E, no caso da EFE, isso se acentuaria em virtude da falta de identidade do campo da Educação Física, cujos cursos de preparação profissional situam-se de longa data justamente na área da saúde (SILVEIRA; PACHECO, 2019).

Completando 12 anos de trabalho com o Currículo do Estado de São Paulo (SÃO PAULO, 2008), novos desafios se apresentam aos professores que atuam nessa etapa de escolarização. Com a promulgação da Lei 13.4I5/17 (BRASIL, 2017), que altera a Lei LDB 9394/96 (BRASIL, 1996), indiretamente se produz a ruptura com a estrutura vigente de estruturação curricular, que deve gerar ressonâncias nos futuros modelos de formação de professores(as) em nível do ensino superior para atuar nesse segmento, ecoados por uma profunda reflexão sobre a escola e sua função social, sobre o currículo, o conhecimento escolar e o papel de cada componente curricular - entre os quais, a própria Educação Física (SILVEIRA, 2019).

Assim, indaga-se como os(as) professores(as) de EFE que não foram formados(as) para atuar nesse formato de proposição curricular - contendo itinerários formativos e dividindo espaço com Artes e Língua estrangeira - poderão desenvolver um currículo dentro das especificidades legais. $O$ que esses(as) profissionais que atuam no EM podem esperar dos prenúncios de um novo currículo? Como podem contribuir com a reforma curricular a partir de suas percepções?

\section{A pesquisa}

Amostra

Compõem a amostra da pesquisa 53 professores(as) de EFE da rede estadual de São Paulo que ministram aulas no ensino médio, sendo 100\% atuantes nas escolas de Programa de Ensino Integral (PEI) com dedicação exclusiva.

Em parceria com a SEE, definiu-se a amostra que seria convidada a participar da pesquisa. No ano de 2018, um questionário no formato google docs foi enviado através da Escola de Formação de Professores - EFAPE, órgão responsável pela formação continuada dos docentes da rede. Todos os dados analisados e interpretados tiveram concordância dos sujeitos oficializada nos Termos de Consentimentos Livre e Esclarecido (TCLE). O projeto foi submetido à Plataforma Brasil e analisado pelo Comitê de Ética da Escola de Educação Física e Esporte da Universidade de São Paulo - EEFEUSP, sendo aprovado sob CAAE 92330918.2 .0000 .5391$. 
Análise dos dados

Foi encaminhado aos participantes um questionário contendo questões fechadas e abertas. Para as questões fechadas, os dados coletados foram tratados utilizando-se estatística descritiva (SILVESTRE, 2007). Para as questões abertas, apoiou-se em Bardin (1977) e Franco (1986), considerando palavras-chave para a criação de índices dos termos que apareceram com maior frequência para análise de conteúdo. Os dados quantitativos e qualitativos relevantes são apontados no formato de tabelas a seguir.

\section{Resultados}

Observando a Tabela I, nota-se a distribuição da amostra relativa às respostas para as questões fechadas.

Tabela I- Distribuição dos resultados das questões fechadas

\begin{tabular}{|c|c|c|c|}
\hline QUESTÕES & RESPOSTAS & $\mathbf{N}^{\mathbf{0}}$ & $\%$ \\
\hline \multirow{3}{*}{ Sexo } & $\sigma^{x}$ & 23 & 43,4 \\
\hline & ㅇ & 28 & 52,8 \\
\hline & Não se identificaram & 2 & 3,8 \\
\hline \multirow[b]{2}{*}{ Região do Estado } & Capital + Grande São Paulo & 14 & 26,4 \\
\hline & Interior & 39 & $73,6 \%$ \\
\hline \multirow{5}{*}{ Satisfação com a profissão } & Muito satisfeito & 22 & $4 I, 5$ \\
\hline & Satisfeito & 22 & $4 I, 5$ \\
\hline & Razoavelmente satisfeito & 7 & 13,2 \\
\hline & Insatisfeito & I & 1,9 \\
\hline & Muito insatisfeito & I & 1,9 \\
\hline \multirow{7}{*}{ Tempo de magistério } & Até 5 anos & 2 & 3,37 \\
\hline & 5 a 10 anos & 8 & $\mid 5, I$ \\
\hline & 10 a 15 anos & 19 & 35,8 \\
\hline & 15 a 20 anos & 8 & $15, I$ \\
\hline & 20 a 25 anos & 8 & $\mid 5, I$ \\
\hline & 25 a 30 anos & 4 & 7,55 \\
\hline & Mais de 30 anos & 4 & 7,55 \\
\hline \multirow{2}{*}{$\begin{array}{l}\text { Conhece a matriz curricular de Educação } \\
\text { Física dos anos finais do ensino fundamental e } \\
\text { do ensino médio? }\end{array}$} & Sim & 51 & 96,22 \\
\hline & Não & 2 & 3,78 \\
\hline \multirow[t]{2}{*}{ Conhece a BNCC? } & Sim & 48 & 90,5 \\
\hline & Não & 5 & 9,5 \\
\hline \multirow{2}{*}{$\begin{array}{c}\text { Considera que o currículo de Educação Física } \\
\text { necessita de revisão? }\end{array}$} & Sim & 39 & 73,6 \\
\hline & Não & 14 & 26,4 \\
\hline
\end{tabular}

Fonte: Os autores, 2018.

As respostas das questões abertas estão organizadas em categorias para a análise de conteúdo. $\mathrm{Na}$ Tabela 2, são apresentadas as duas categorias definidas a partir das respostas à questão I - Quais revisões você faria no currículo?; dela derivam-se, na Tabela 3, as subcategorias definidas a posteriori a partir da categoria a) Nos conteúdos. Por fim, a Tabela 4 refere-se à questão 2 - Quais conteúdos você mais gosta de ensinar?

Olhar de professor, Ponta Grossa, v. 24, p. I-2I, e-I5233.010, 2021.

Disponível em <https://revistas2.uepg.br/index.php/olhardeprofessor> 
O currículo de Educação Física no Ensino Médio do estado de São Paulo na voz dos professores...

Tabela 2 - Quais revisões você faria no currículo?

\begin{tabular}{|c|c|c|}
\hline Sugestões de revisão com foco: & Número de respostas (39) & $\%$ \\
\hline a) Nos conteúdos & 29 & 74,3 \\
\hline $\begin{array}{c}\text { b) Em outros aspectos (nomenclaturas, situações } \\
\text { de aprendizagem e materiais de apoio) }\end{array}$ & 10 & 25,7 \\
\hline
\end{tabular}

Fonte: Os autores, 2018.

Tabela 3 - Subcategorias para as sugestões com foco nos conteúdos

\begin{tabular}{|c|c|c|}
\hline a) Sugestões com foco nos conteúdos & $N^{\circ}$ de respostas (29) & $\%$ \\
\hline I- Ajustes de aprofundamento e realocação & 9 & 3 I \\
\hline $\begin{array}{c}\text { 2- Redistribuição ou troca devido à inadequação de tempo, } \\
\text { espaço e/ou materiais disponíveis }\end{array}$ & 7 & $24, \mathrm{I}$ \\
\hline 3- Ampliação de conteúdos voltados à prática e ao movimento & 6 & 20,6 \\
\hline $\begin{array}{c}\text { 4- Alterações nos conteúdos devido afastamento/proximidade } \\
\text { com a cultura da comunidade }\end{array}$ & 5 & 17,2 \\
\hline \begin{tabular}{l} 
5- Modificação em conteúdos para provocar interesse dos alunos \\
\hline
\end{tabular} & 2 & 7,1 \\
\hline
\end{tabular}

Fonte: Os autores, 2018.

Tabela 4 - Quais conteúdos você mais gosta de ensinar?

\begin{tabular}{|c|c|c|}
\hline Termos mais citados & $\begin{array}{c}\text { Número de respostas contendo os } \\
\text { termos }\end{array}$ & $\%$ \\
\hline Saúde & I I & 20,7 \\
\hline Esporte & 9 & 16,9 \\
\hline Modalidades esportivas coletivas & 8 & 15 \\
\hline Corpo humano & 7 & 13,2 \\
\hline Qualidade de vida & 4 & 7,5 \\
\hline Ginástica & 3 & 5,6 \\
\hline Exercícios & 2 & 3,7 \\
\hline Cultura corporal & 2 & 3,7 \\
\hline Capacidades físicas & 2 & 3,7 \\
\hline Jogos & 2 & 3,7 \\
\hline Dança & I & $\mathrm{I}, 8$ \\
\hline Brincadeiras & I & 1,8 \\
\hline Atividade física & I & $\mathrm{I}, 8$ \\
\hline Lutas & I & 1,8 \\
\hline Não responderam & 2 & 3,7 \\
\hline
\end{tabular}

Fonte: Os autores, 2018.

\section{Discussão}

\section{Caracterização da amostra}

A amostra é composta por 53 sujeitos, sendo 23 do sexo masculino, 28 do sexo feminino e 2 indivíduos que não se identificaram em nenhuma categoria.

Uma característica interessante é a participação massiva de docentes da região interior do Estado de São Paulo, com 39 sujeitos, representando 73,6\% da amostra. Este dado permite observar que profissionais de fora da região chamada capital e grande São Paulo tiveram um maior engajamento

Olhar de professor, Ponta Grossa, v. 24, p. I-2I, e-I5233.010, 202 I.

Disponível em <https://revistas2.uepg.br/index.php/olhardeprofessor> 
na participação desta pesquisa disponível no sistema, abrangendo as escolas com atendimento em tempo integral do Estado.

Parece relevante destacar que 44 professores $(83 \%)$ responderam estar satisfeito ou muito satisfeito com a profissão. No outro extremo, insatisfeito e muito insatisfeito somaram apenas 2 indivíduos, enquanto 7 se situaram na categoria razoavelmente satisfeito. De modo mais pragmático, os resultados no extremo positivo de satisfação com a profissão podem ser interpretados com base em três possibilidades: I) responderam positivamente à questão em virtude de um comportamento defensivo ou precavido, para evitarem represálias, apesar da garantia do sigilo dos dados; 2) em decorrência da amostra ser essencialmente do interior do Estado (73,6\%), ela congrega docentes com estilos de vida menos conturbados que os levados na metrópole, que poderiam sentir-se mais satisfeitos; 3) ○ fato de $100 \%$ dos participantes ministrarem aulas nas escolas PEl, com dedicação exclusiva a uma unidade escolar e gratificação de $75 \%$ sobre o salário, poderia promover um maior e melhor envolvimento e satisfação com a atividade profissional.

Analisando-se o tempo de experiência no magistério, constata-se que 71, I\% dos participantes apresenta uma experiência na rede compreendida entre 6 a 25 anos, sendo a faixa de maior presença, com $35,8 \%$ dos docentes entre II a I5 anos e 30,2\% para as faixas entre I5 a 20 anos e 20 a 25 anos (com 15,1\% para cada agrupamento). Esse dado parece ser produto das implicações do processo seletivo das escolas PEl, uma vez que, para atuar nessas instituições, cada professor precisa apresentar um projeto de ensino e passar por entrevista nas diretorias regionais de ensino com a equipe responsável pelas instituições. De tal modo, os números relativos ao tempo de magistério da amostra indicam que os(as) professores(as) selecionados(as) para atuarem com a EFE têm mais de 10 anos de experiência profissional $(81,1 \%)$, característica que pode refletir positivamente na qualidade do ensino e articulação do trabalho pedagógico e coletivo da escola, expresso no projeto político-pedagógico.

Com relação ao conhecimento de documentos de orientação curricular, $96,22 \%$ dos participantes declaram conhecer o currículo de Educação Física do Estado de São Paulo e 90,5\% declaram também conhecer a BNCC. Os dados revelam que as ações de formação continuada, como os cursos promovidos pela SEE e as orientações regionais e locais de cada escola, mostraram-se eficientes para a divulgação dos documentos. Nesse mesmo sentido, a inserção midiática do Ministério da Educação e as ações divulgadoras da SEE parecem ter favorecido o acesso às novas orientações advindas da BNCC para o EM. Todavia, em decorrência do processo seletivo enfrentado pelos professores para atuarem nas escolas PEl, bem como das implicações de estudo e permanência que estas instituições exigem, esperava-se contar com 100\% da amostra conhecendo o currículo da disciplina.

Olhar de professor, Ponta Grossa, v. 24, p. I-2I, e-I5233.010, 2021.

Disponível em <https://revistas2.uepg.br/index.php/olhardeprofessor> 
O currículo de Educação Física no Ensino Médio do estado de São Paulo na voz dos professores...

Por fim, na caracterização da amostra, destacam-se as respostas positivas para a questão relacionada à necessidade de uma revisão do currículo atual de Educação Física no EM, que embasam a continuidade da discussão. Das 53 respostas, 39 sujeitos (73,6\%) afirmam que o currículo necessita de revisão. Assim, considerando o tempo de experiência profissional e o reconhecimento dessa experiência na seleção para participação das escolas PEl, passa-se a analisar o que os professores propõem de alterações.

Quais revisões você faria no currículo?

Em conformidade com a Tabela 2, é importante não negligenciar que 14 profissionais (26,4\%) entendem que o currículo NÃO precisa ser revisto. Surpreende que esses sujeitos, de distintas regiões do Estado, não apontem a necessidade de mudanças em um documento há 12 anos em vigência, entendendo que a diversidade regional pode gerar uma dificuldade individual no trabalho com um currículo que é único para o Estado e que, especificamente no caso da EFE, revela uma tentativa de agregar linhas pedagógicas historicamente polissêmicas (CORREIA, 2016).

O dado pode apontar para duas possibilidades, a saber: que esta parcela de professores(as) está bem adaptada ao currículo do Estado de São Paulo (SÃO PAULO, 20II) e satisfeita com o seu desenvolvimento; ou que estes participantes não tiveram interesse em se engajar em debates mais profundos sobre mudanças no documento como propõem as outras questões.

Em prosseguimento, a atenção se dará aos 39 sujeitos $(73,6 \%)$ que responderam SIM para a necessidade de revisões no currículo. As respostas dos professores incidem para duas vertentes de sugestões de mudanças, divididas nas categorias com foco: a) "Nos conteúdos”; e b) "Em outros aspectos (nomenclaturas, situações de aprendizagem e materiais de apoio)".

A categoria "a", identificada partindo de sugestões com foco "Nos conteúdos", corresponde a $29(74,3 \%)$ das respostas que reforçam a necessidade de revisões no currículo. Nesse aspecto, é possível constatar a premissa (3) da investigação, pois a maioria das respostas dos docentes em relação à possível reformulação do currículo incidiu sobre "o quê ensinar". Devido ao caráter aberto das questões e à guisa de uma análise detalhada das respostas, permitiu-se dividir em 5 subcategorias as respostas pertencentes à categoria a) Nos conteúdos, cuja discussão segue na sequência, com base na Tabela 3.

Um percentual de destaque (31\%) foi inserido na subcategoria I - Ajustes de aprofundamento/realocação, na qual 9 sujeitos explicitaram a demanda por explorar, aprofundar ou realocar certos conteúdos, sem prosseguir com justificativas pormenorizadas. Como exemplos, podese destacar respostas sucintas como: "explorar mais a saúde e a fisiologia do corpo humano"; "aprofundar 
conteúdos dos esportes, ginásticas, sedentarismo e obesidade"; "ser revista a questão das ginásticas"; "mais conteúdos sobre anatomia"; "o conteúdo não está sendo aprofundado"; "os conteúdos se repetem".

Vale ressaltar que algumas respostas também acabam por evidenciar a apropriação e a proximidade dos docentes com determinadas manifestações da cultura corporal de movimento e com temas da área da "saúde" e qualidade de vida. Esta informação suscita uma discussão acerca da formação profissional do(a) professor(a) de EFE na área da saúde e do forte vínculo com a própria saúde, o esporte e a ginástica e/ou exercício.

Desse modo, identifica-se a premissa ( $I$ ) da investigação, pois o problema da falta de identidade de área claramente definida para a educação física apresentada por Tani (1996, 1998, 201 I) parece se materializar na formação profissional (inicial e continuada), na estruturação de documentos curriculares e na prática docente. Por um lado, o futuro professor de Educação Física ingressa no ensino superior num curso da área da saúde; quando formado tem seu credenciamento no Conselho Regional como profissional da saúde e é, inclusive, reconhecido pela Portaria 639/2020 (BRASIL, 2020) como profissional da mesma área para enfrentamento do Covid-19. Por outro, ao iniciar sua carreira no magistério para atuar na educação básica, se depara com um currículo de EFE inserido no campo das “Linguagens”.

Em outro sentido, os excertos acabam por corroborar os destaques de Neira (201 I) sobre o currículo do Estado, que nota a prevalência dos conteúdos que priorizam atividades físicas, ressaltando o viés biológico e o estilo de vida ativo, que, por sua vez, coaduna com o tipo de formação profissional na maioria das faculdades de educação física, mas pode estar aquém do que se faz entender por uma educação física na área das Linguagens pressuposta pelo próprio currículo.

Nas demais subcategorias referentes à categoria a) Nos conteúdos, os sujeitos aprofundaram mais suas respostas, propondo justificativas mais específicas em suas sugestões, como analisado na sequência.

Sete respostas, correspondentes a 24,1\%, compõem a subcategoria 2 - Redistribuição devido à inadequação de tempo, espaço e/ou materiais disponíveis. Estas respostas justificariam modificações na apresentação dos conteúdos baseadas em certas dificuldades estruturais da prática docente. Como exemplos encontrados podem ser citados os excertos: "sintetizar os conteúdos"; "ausência de estrutura e material adequado para trabalhar certos conteúdos esportivos"; "Apesar de usar de criatividade, necessitamos de materiais específicos às atividades"; "necessidade de material desportivo de qualidade e em quantidade suficiente".

Uma única resposta relativa a comprimir ("sintetizar") a quantidade de conteúdos dá a ideia de inadequação de tempo para trabalhar com o currículo no formato corrente. Já os outros trechos não expõem a necessidade de trocar um conteúdo por outro de maneira clara, mas evidenciam - ao trazer

Olhar de professor, Ponta Grossa, v. 24, p. I-2I, e-I5233.010, 2021.

Disponível em <https://revistas2.uepg.br/index.php/olhardeprofessor> 
O currículo de Educação Física no Ensino Médio do estado de São Paulo na voz dos professores...

a questão estrutural/material - uma obviedade que, embora não remeta à sugestão de modificação curricular, aponta um pré-requisito para a prática docente: nenhum currículo poderá ser seguido de modo consistente sem os recursos adequados. Não se pode romantizar a função de professor(a), isentando a administração pública de prover as escolas com o mínimo de preparo e estrutura para um currículo. Entende-se que as falas sobre estes problemas estruturais denunciam precárias condições de trabalho no que concerne ao acesso a materiais e estrutura adequada ao trabalho. Dadas as raras alternativas que os docentes das redes têm para fazer suas críticas e sugestões, compreende-se o porquê de as respostas transitarem nesse âmbito mesmo quando deveriam refletir apenas demandas por mudanças curriculares.

A seguir, 6 respostas $(20,6 \%)$ foram enquadradas na subcategoria 3 - Ampliação de conteúdos voltados à prática e o movimento. Como excertos, encontram-se: "A educação fisica do ensino médio é muito teórica (...) precisamos de um maior equilibrio na distribuição dos temas para que nossos alunos tenham tempo efetivo para a prática de atividade fisica"; "Torná-los mais práticos"; "Atualmente, mais da metade da população brasileira encontra-se com sobrepeso ou certo grau de obesidade, o que certamente acarretará problemas de saúde futuros (...) alunos estão sedentários e não gostam de praticar exercícios fisicos”.

É interessante notar que esses temas estão fortemente presentes nos eixos temáticos entrecruzados com os eixos de conteúdo no currículo, fato destacado por Neira (20l I); entretanto, tal presença parece não ser suficiente para alguns participantes. Observa-se que surgem comentários sobre o sedentarismo dos(as) alunos(as). Em vista dos apontamentos, destaca-se o perigo de se confundir o espaço escolar com um espaço para prática de atividades físicas, que segundo Tani (20ll) deslegitimaria a EFE como uma disciplina do currículo, distanciando-a das discussões políticopedagógicas e aproximando-a de uma atividade de caráter extracurricular, passível de sofrer intervenções de um(a) bacharel, ou mesmo técnicos em recreação.

Na subcategoria 4 - Alterações nos conteúdos devido afastamento/proximidade dos conteúdos com a cultura da comunidade, inserem-se 5 respostas (17,2\%). Encontram-se excertos contraditórios relativos à "popularidade" dos conteúdos, como "incluir mais modalidades não tão populares" versus "gostaria que houvesse uma revisão nas questões esportivas com algumas trocas por esportes mais presentes na cultura do brasileiro" ou "revisões que trabalhem com conteúdo mais próximo da realidade do aluno".

Tem-se a impressão de que, enquanto alguns profissionais se sentem mais à vontade ensinando conteúdos mais conectados com a cultura das comunidades, outros, em oposição, entendem que há necessidade de substituir alguns conteúdos por outros menos conhecidos da comunidade, para, desta forma, ensinar algo novo.

Vale a pena destacar o fato de que o currículo aumenta em grau de complexidade de eixos de conteúdo e eixos temáticos desde $\circ$ 60 ano do ensino fundamental, partindo de experiências inseridas 
em contexto local, avançando para outras culturas regionais brasileiras e depois para aquelas manifestações da cultura de movimento situadas nas culturas de outros países. Nesse aspecto, se $96,22 \%$ dos docentes afirmam conhecer o currículo do ensino fundamental e do ensino médio de EFE, infere-se que deveriam ter demonstrado conhecimento desta progressão.

Na subcategoria 5 - Modificação em conteúdos para provocar interesse dos alunos, presente em 2 respostas (7,I\%), apresentam-se falas como: "é preciso reformular alguns dos temas trabalhados com pouco interesse por parte dos alunos" ou "tornar os assuntos mais interessantes". O questionamento parece afligir os docentes, pois frequentemente a ideia de construir um currículo e uma prática mais "atrativos" para discentes emerge inclusive nas próprias justificativas dos documentos.

$\mathrm{Na}$ prática, tentar alterar obsessivamente os métodos e conteúdos curriculares com o intuito de atrair todos da mesma forma é, segundo Lajonquière (1999), uma tarefa de onipotência impossível aos(às) professores(as) que, no entanto, embasa boa parte dos discursos que responsabilizam a categoria profissional no sentido de encontrar soluções para a problemática.

Por isso, a impossibilidade de atrair os(as) alunos(as) por igual - a despeito de qual seja o conteúdo - deve ser relembrada como contingência de quaisquer processos educativos. Considere-se que existe o ensino de EFE em instituições públicas, privadas, militares, bilíngues, etc. Claro está que diferenças entre elas existem, no ensino, nos conteúdos, nos métodos, na avaliação e na aprendizagem. E, talvez, a unidade utópica de um documento norteador seja útil aí mesmo, como proposta que segue certos preceitos, mas que, em parte, certamente sucumbirá, seja por causa de outras características contextuais incontroláveis e intangíveis pelo controle curricular, seja pela reconfiguração dos modos próprios de atuação de cada professor(a), que socializa os conhecimentos de forma pessoal, o teacher's knack. (SILVEIRA; PACHECO, 2019).

Dos 39 sujeitos que entendem que o currículo necessita de revisão, $10(25,7 \%)$ não mencionaram diretamente os conteúdos como foco de revisões necessárias; por isso, suas respostas passaram à categoria b) Em outros aspectos (nomenclaturas, situações de aprendizagem e materiais de apoio), que versa sobre revisões em outros aspectos do currículo (Tabela 2).

Em suas respostas, os(as) professores(as) descreveram sucintamente apenas necessidades de mudança na forma de "revisão geral", "atualização de nomenclaturas" e "renovação periódica", por exemplo. Outras respostas mencionaram possível adequação nos materiais de apoio, com destaque para os cadernos de professor, sugerindo melhorias nas "situações de aprendizagem" ou "estabelecer sequências pedagógicas lógicas". Pelo exposto, é possível afirmar que este percentual de professores(as) declara a necessidade de mudanças mais globais na estrutura do currículo ou nos seus respectivos materiais de apoio (cadernos do professor), para melhor desenvolvê-los em sua prática, apesar de não descartarem em nenhum momento sua utilidade.

Olhar de professor, Ponta Grossa, v. 24, p. I-2I, e-I5233.010, 2021. 
O currículo de Educação Física no Ensino Médio do estado de São Paulo na voz dos professores...

"Quais conteúdos você mais gosta de ensinar em Educação Física?"

Os participantes tiveram a liberdade de escrever suas preferências de conteúdos da EFE em sua prática docente (Tabela 4). Em ordem decrescente, os termos que apareceram com mais frequência nas respostas foram: "saúde" em II; "esporte" em 9; "modalidades coletivas" em 8; "corpo humano" em 7; "qualidade de vida" em 4; e "ginástica" em 3 respostas.

Observa-se a reiterada suposição de que os(as) professores(as) apresentam uma tendência relevante de proximidade aos temas da saúde e esportivo, presentes como disciplinas de forma significativa nos cursos de formação inicial do ensino superior. Destaca-se que das II vezes em que foi citado o termo "saúde", em 4 respostas ele apareceu descrito exatamente como está apresentado em um dos "eixos temáticos" do Currículo do Estado de São Paulo, a saber: "Corpo, saúde e beleza", o que demonstraria uma faceta da apropriação efetiva do modo específico de como o documento está delineado.

Nos relatos identificados, se torna evidente a concepção da premissa (I) e seu desdobramento na premissa (2), pois considerando-se a indefinição de identidade de área, os(as) professores(as) de EFE encontram as suas próprias formas de exercer a prática docente, numa adaptação do currículo às suas próprias concepções e experiências de ensino, que no caso coadunam com os conhecimentos de "saúde" e "esportivos" comumente relacionados à área de Educação Física. Alguns excertos sobre os conteúdos prediletos ensinados pelos participantes ilustram claramente este viés: "a importância do exercício fisico para saúde e qualidade de vida"; "os beneficios da prática de educação fisica em relação à saúde e a relação direta com a boa alimentação para uma vida saudável."; "as modalidades esportivas: fundamentos e regras".

Em paralelo, em algumas respostas, termos como "respeito", "solidariedade" ou "cidadania" apareceram como conteúdos associados às preferências dos(as) docentes, mas não foram incluídas na Tabela 4, merecendo, entretanto, um comentário. Cabe observar que os conceitos de "responsabilidade social" compõem todo o processo educativo e não são exclusivos de uma disciplina. Apesar disso, tais respostas apresentadas como conteúdos prediletos reforçam a ideia de Tani (20II) de que a educação brasileira tem assumido papéis sociais mais amplos do que deve, confundindo sua função precípua com os papéis da educação no sentido lato. Isso sufoca a própria instituição escolar em suas atribuições e, consequentemente, afeta as disciplinas e os objetivos dos(as) docentes em sua prática profissional, gerando indiretamente alguns prejuízos que penetram nas especificidades de cada área. Como afirmam Silveira e Pacheco (2019), professores(as) de EFE muitas vezes modificam sua prática docente devido a uma responsabilização compulsória para cumprir inúmeras outras funções 
impossíveis de serem contempladas objetivamente. Assim, esses pilares da convivência escolar e social não podem ser confundidos com conteúdos específicos da área de EFE.

\section{Considerações finais}

O estudo realizado buscou atender a questão central da pesquisa, ou seja, como as percepções dos professores de EFE do EM acerca do currículo, a partir de experiências advindas de sua utilização na intervenção profissional, poderiam influenciar no processo de estruturação da reformulação curricular - gerada pela Lei 13.4I5/I7 (BRASIL, 20I7) e norteada pelas orientações da BNCC (BRASIL, 2018) - na qual para o EM estão previstos vaga e peculiarmente "estudos e práticas" de educação física na área de Linguagens.

Dentre a caracterização da amostra representada por professores experientes com mais de 10 anos de magistério $(81,1 \%)$ e muito satisfeitos ou satisfeitos com a profissão (83\%), as respostas observadas materializam as preocupações dos(as) docentes direcionadas, especialmente, aos conteúdos de ensino. Os resultados reforçam a ideia contida na premissa (3) - que advoga que, em decorrência das demandas da prática docente, as percepções dos(as) professores(as) sobre possíveis alterações no currículo incidiriam sobre "o quê ensinar", sugerindo que a seleção de conteúdos do currículo para a prática docente ocorre com base num caráter dialético, o qual, simultaneamente, influencia e é influenciado pela interpretação do contexto em que atuam tais professores(as).

Ademais, essa informação esbarra na problemática relativa à dificuldade de organização de conhecimentos a serem ensinados na EFE em virtude da falta de uma concepção de área claramente definida para educação física. Assim, ao se constatar que as atenções dos docentes em situações de intervenção profissional no magistério estão centradas nos conteúdos, é possível esperar que cada professor olhe para esses conteúdos de formas distintas daquelas esperadas no documento oficial, interpretando-os em conformidade com as experiências oriundas da sua história de vida e (res)significando-os a partir das experiências estabelecidas ao longo do processo de formação, inicial e continuada, gerando um conhecimento pessoal de cada professor sobre o que e como ensinar, bem como sobre como avaliar a aprendizagem. Nesse sentido, vale ressaltar que estudos futuros relativos a esses conhecimentos e suas gêneses são de grande importância para o processo de preparação profissional.

A despeito de críticas ou de sugestões feitas pelos participantes na presente pesquisa, observase que a EFE tende a ser muito prejudicada com a reforma prevista para $\circ \mathrm{EM}$. Ao que indicam os dados deste trabalho, o Currículo do Estado de São Paulo (SÃO PAULO, 20I I), apesar das possíveis críticas a ele endereçadas, apresenta um delineamento através de seus eixos de conteúdo e eixos temáticos propostos nos quais os professores de EFE reconhecem certos conhecimentos, sob a forma

Olhar de professor, Ponta Grossa, v. 24, p. I-2I, e-I5233.010, 2021.

Disponível em <https://revistas2.uepg.br/index.php/olhardeprofessor> 
O currículo de Educação Física no Ensino Médio do estado de São Paulo na voz dos professores...

de conteúdos como pertencentes às suas práticas. Como foi visto, professores(as) demonstraram uma apropriação do documento de considerável solidez, com especial atenção ao eixo de conteúdo "esporte" e ao eixo temático "corpo, saúde e beleza", sobre os quais as propostas de ajustes incidiram com maior ênfase. Retomando as definições acerca de currículo feitas por Goodson (2002), pode-se dizer que a prática docente em EFE a partir do Currículo do Estado de São Paulo vem inventando e, portanto, revelando sua própria tradição, apropriando-se de certos conteúdos do documento que mais condizem com o que os docentes entendem ser o papel da disciplina no EM, certamente influenciados por sua formação inicial, continuada.

Assim, também se faz necessário lançar mão de uma avaliação positiva do Currículo do Estado de São Paulo (SÃO PAULO, $20 \mathrm{I}$ I), cuja sistematização permitiu certo alinhamento ou direcionamento da prática docente, ao menos, para a amostra desta pesquisa.

As percepções dos professores de EFE poderiam contribuir com outro fator relevante sobre a reestruturação curricular, referente à revisão da inclusão da EFE como disciplina na área das Linguagens. Isso não significa que a EFE possa fazer interlocuções com outras áreas do currículo escolar, contudo, restringi-la à área Linguagens, campo eminentemente dissociado da estrutura dos cursos de formação inicial do próprio profissional, pode se constituir como um projeto educativo fadado ao fracasso caso não reavalie amplamente a situação. Ou seja, as ambiguidades presentes no cerne do próprio currículo - também resultantes da indefinição do corpo de conhecimentos da área da Educação Física - se refletem na prática dos(as) professores(as), que buscam atuar na intervenção profissional ajustando a utilização do currículo às concepções pessoais (premissa I), fato que, no entanto, não pode ser traduzido simplificada e irresponsavelmente como culpa desses profissionais. Consequentemente, na esperada reforma curricular obrigatória, a tendência é que tais divergências permaneçam e ampliem os desafios em EFE.

Presume-se que, em essência, a BNCC (2018) não trará novidades positivas à prática docente de educação física no EM, tampouco colaborará com a construção de um currículo mais conciso e de um caminho mais definido para a EFE. Ao contrário, apagando a Educação Física como um componente e sugerindo "estudos e práticas" de Educação Física ainda na área de "Linguagens", supõe-se que os(as) professores(as) de EFE continuarão interpretando e adaptando os currículos alterados pela base da mesma forma que o fizeram com o Currículo do Estado de São Paulo nesses 12 anos. Isto é, atuando de acordo com o que propagam os cursos formação de professores de EFE, em sua grande maioria, atendendo de modo idiossincrático (mas não por isso menos criativos) às demandas vinculadas às questões da saúde e do fenômeno esportivo, a despeito do que a fundamentação teórica dos documentos oficiais proponha. 
Não menos importante, a falta de identidade acadêmica da Educação Física problematizada por Tani $(1996,1998,201 \mathrm{I})$ também ficou evidente nas respostas que vislumbram um currículo mais voltado para a prática per se de atividade física na escola. Não obstante o diagnóstico de sedentarismo do alunado, como problema de saúde pública levantado pelos professores, é possível perceber que o combate ao problema não coaduna com as proposições da EFE previstas no currículo na área de Linguagens ao longo da escolarização. Ou seja, as percepções e entendimentos dos docentes com relação à EFE parecem caminhar para um lado, enquanto os princípios curriculares apontam para outra direção, porquanto na ordem do dia permaneça o problema da indefinição no campo epistemológico da Educação Física, quiçá ainda muito distante de resolução.

Quando questionados sobre a necessidade de mudança no currículo atual, 39 (73,6\%) participantes concordaram e, inclusive, propuseram possíveis caminhos para tanto, demonstrando engajamento e interesse no sentido de modificar o status quo. Ou seja, a premissa (2), de que os(as) professores(as) apresentam conhecimentos e percepções oriundos da prática docente que podem e devem ser expressos, para que possam ser considerados na elaboração de reformas curriculares, emerge como uma relevante informação, que alimentará novas pesquisas.

Faz-se digno de nota que parte das mudanças sugeridas transcende questões sumamente curriculares e traz à superfície os conhecidos problemas estruturais, psicológicos e sociais que envolvem a educação, como, por exemplo, falta de materiais, espaço e (des)interesse do alunado, o que não diminui sua relevância, mas aponta uma inadequação de perspectiva.

Sem dúvida, uma limitação deste tipo de pesquisa refere-se à distância entre as respostas obtidas (descritas) e a prática docente in loco (atuação na escola propriamente dita). Ainda que tal prática docente cotidiana a partir do currículo não tenha sido apreciada na pesquisa em foco, futuros trabalhos nesse sentido trariam importantes contribuições para a discussão do tema, aproximando-se cada vez mais da realidade escolar, que embora seja conhecida fonte de produção dos saberes docentes ainda permanece negligenciada na elaboração de currículos.

Deve-se insistir que, possivelmente, os(as) professores(as) de EFE percorreram uma trajetória de formação no ensino básico constituída majoritariamente em moldes mais tradicionais, o que certamente influencia suas concepções a respeito da disciplina a ser ensinada no EM. Por conseguinte, a lógica da formação universitária também não se difere muito do que foi a do ensino básico, transitando também num modo característico de ensino de determinados conteúdos, com certos objetivos, métodos e tipos de avaliação tradicionalmente estabelecidos e validados. Assim, é possível concluir que os docentes de EFE, tendo vivido experiências formativas tributárias das vertentes “clássicas" da área (esporte e saúde), tendem a perpetuá-las em sua prática docente, o que não impede a produção de diferentes saberes da prática que deveriam ser apoiados por um currículo que não está

Olhar de professor, Ponta Grossa, v. 24, p. I-2I, e-I5233.010, 2021.

Disponível em <https://revistas2.uepg.br/index.php/olhardeprofessor> 
O currículo de Educação Física no Ensino Médio do estado de São Paulo na voz dos professores...

nem estará, após a reforma, imune a críticas construtivas como as que aqui foram consideradas a partir da voz dos(as) professores(as).

\section{Referências}

BARDIN, L. Análise de conteúdo. Lisboa: Edições 70, 1977.

BRASIL. Lei I34I5. Altera as leis 9394/96 e a I I494/07. Brasília, DF, 2017.

BRASIL. BNCC. Base Nacional Comum Curricular - Ensino Médio - $3^{\text {a }}$ versão. Brasília: MEC.

Ministério da $\quad$ Educação, $2018 . \quad$ Disponível em:

http://basenacionalcomum.mec.gov.br/images/BNCC_publicacao.pdf. Acesso em: I I abr. 2020.

BRASIL. Lei 4024/6I. Lei de Diretrizes e Bases da Educação Nacional. Brasília, DF, I96I.

BRASIL. Lei 5692/7I. Lei de Diretrizes e Bases da Educação Nacional. Brasília, DF, I97I.

BRASIL. Lei 9394/96. Lei de Diretrizes e Bases da Educação Nacional. Brasília, DF, 1996.

BRASIL. Parâmetros Curriculares Nacionais: Educação Física, Ensino Médio. Brasília, DF: MEC, 1998.

BRASIL. Ministério da Saúde. Portaria N 639/20. Brasília, DF, 2020.

CORREIA, W. R. Educação Física Escolar: o currículo como oportunidade histórica. Revista Brasileira de Educação Física e Esporte, São Paulo, v.30, p.83I-836, 2016.

CORREIA, W.R. Educação Física no EM questões impertinentes. São Paulo: Fontoura, 20 I I.

FRANCO, M. L. P. B. O que é análise de conteúdo? Cadernos da Psicologia da Educação, São Paulo, v.7, p. I-3I, ago. 1986.

FRANCO, M. A. S. R. S.; Prática pedagógica e docência: um olhar a partir da epistemologia do conceito. Revista Brasileira de Estudos Pedagógicos. Brasília, v.97, n.247, p.534-55I, 2016.

GOODSON, I. F. Currículo: teoria e história. Petrópolis: Vozes, 2002.

KRAWCZYK, N. O ensino médio no Brasil. São Paulo: Ação educativa, 2009. Disponível em: http://www.bibliotecadigital.abong.org.br/bitstream/handle// |465// |40// 763.pdf?sequence= | \&isAllow ed=y. Acesso em: II abr. 2020.

KUENZER, A. Z. O ensino médio agora é para vida: entre o pretendido, o dito e o feito. Revista Educação e Sociedade, ano XXI, n.70, 2000.

LAJONQUIÈRE, L. Infância e ilusão (psico)pedagógica: escritos de psicanálise e educação. São Paulo: Vozes, 1999.

LOPES, A. C.; MACEDO, E. Teorias de currículo. São Paulo: Cortez, 201 I.

MACEDO, R. S. Currículo: campo, conceito e pesquisa. RJ: Vozes, 2007.

Olhar de professor, Ponta Grossa, v. 24, p. I-2I, e-I5233.010, 2021.

Disponível em <https://revistas2.uepg.br/index.php/olhardeprofessor> 
NEIRA, M. G. A proposta curricular do Estado de São Paulo na perspectiva dos saberes docentes. Revista Brasileira de Educação Física e Esporte, São Paulo, v.25, p.23-27, 201 I.

NEIRA, M. G. Incoerências e inconsistências da BNCC de Educação Física. Revista Brasileira de Ciências do Esporte, v.40, p.215-223, 2018.

ROLDÃO, M. C. Função docente: natureza e construção do conhecimento profissional. Revista Brasileira de Educação, v. I2, n.34, 2007.

SACRISTÁN, J.G.; PÉREZ GÓMEZ, P.A.I. Compreender e transformar o ensino. Porto Alegre: Artmed, 2000.

SÃO PAULO (ESTADO). Secretaria da Educação. Currículo do Estado de São Paulo Linguagens, códigos e suas tecnologias. Educação Física. São Paulo, $201 \mathrm{l}$.

SÃO PAULO (ESTADO). Secretaria da Educação. Proposta curricular do Estado de São Paulo Educação Física. São Paulo, 2008.

SÃO PAULO (ESTADO). Secretaria da Educação. Curso específico de formação aos ingressantes nas classes docentes do quadro do magistério, 2016. Disponível em: http://www.rededosaber.sp.gov.br/portais/Portals/I80/Regulamento_formacao_Ingressantes_PEBI_Et apa\%20I\%20\%20Fundamentos\%20B\%C3\%A I sicos\%20\%20 l ed.pdf. Acesso em: II abr. 2020.

SILVEIRA, S. R. Educação física no EM: subsídios para a uma política pública. In: CARREIRA FILHO, D.; CORREIA, W.R.; MOURA, D.L.; SILVEIRA, S.R. Educação Física no Ensino Médio: questões e reflexões. Curitiba: CRV, 2019.

SILVEIRA, S. R.: PACHECO, G. F. Z. Autonomia e prática docente em educação física escolar. Revista Brasileira de Educação Física e Esporte, v. 33, p. I5-2I, 2019.

SILVESTRE, A. L. Análise de Dados e Estatística Descritiva. São Paulo: Escolar Editora, 2007.

TANI, G. Cinesiologia, educação física e esporte: ordem emanante do caos na estrutura acadêmica, Motus Corporis, Rio de Janeiro, v.3, n.2, p.9-50, 1996.

TANI, G. Educação física escolar no Brasil: Seu desenvolvimento, problemas e propostas. In: Anais do Seminário Brasileiro em Pedagogia do Esporte. Santa Maria: Universidade Federal de Santa Maria, 1998.

TANI, G. Leituras em educação física: retratos de uma jornada. São Paulo: Phorte, 20 I I.

Recebido em: 29 de abril de 2020.

Versão corrigida recebida em: 03 de setembro de 2020.

Aceito em: 03 de setembro de 2020.

Publicado online em: 19 de março de 2021 .

Olhar de professor, Ponta Grossa, v. 24, p. I-2I, e-I5233.010, 202 I.

Disponível em <https://revistas2.uepg.br/index.php/olhardeprofessor> 